\title{
Direct Restoration of Endodontically Treated Teeth: a Brief Summary of Materials and Techniques
}

\author{
Sema Belli ${ }^{1}$ Oguz Eraslan ${ }^{2} \cdot$ Gurcan Eskitascioglu ${ }^{3,4}$
}

Published online: 12 October 2015

(C) Springer International Publishing AG 2015

\begin{abstract}
The restoration of endodontically treated teeth remains a challenge. The success of the final restoration depends mostly on the structure of the remaining tooth. Although the materials and procedures available today result in successful restoration of root-filled teeth via direct (in situ) techniques, one should first consider the amount of the coronal tooth structure remaining as well as the functional requirements. Restoration using direct composite resin is a good treatment option, but polymerization shrinkage is one of the major limitations of this material. The application of various base materials under the composite resin is an effective method. Covering the cusps with the restorative material is another option to save the remaining tooth structure; however, some materials may be unsuitable in stress-bearing areas. Materials applied to the orifice of a root canal also have a major effect on tooth biomechanics. This article reviews the direct restoration of endodontically treated teeth and discusses the current materials and techniques used for this purpose.
\end{abstract}

This article is part of the Topical Collection on Dental Restorative Materials

Sema Belli

sbelli@selcuk.edu.tr

1 Department of Endodontics, Faculty of Dentistry, Selcuk University, Konya, Turkey

2 Department of Prosthodontics, Faculty of Dentistry, Selcuk University, Konya, Turkey

3 Department of Prosthodontics, Faculty of Dentistry, Yuzuncuyil University, Van, Turkey

4 Department of Prosthodontics, Faculty of Dentistry, Gazi University, Ankara, Turkey
Keywords $\mathrm{NaOCl} \cdot$ EDTA $\cdot$ MTAD $\cdot$ Fiber post $\cdot$ One-piece milled zirconia post $\cdot$ Stress $\cdot$ Flared root $\cdot$ Finite element analysis

\section{Introduction}

The outcome of endodontic treatment is influenced by several factors, and among these, microbial contamination is one of the major causes of endodontic failure [1, 2]. Therefore, the root canal filling must seal the canal walls both apically and laterally to prevent microorganisms or tissue fluids from entering the canal space.

Leakage into the root canal system may occur via one of four routes [3]: (1) through the apical foramen, which is between the root filling material and the root canal wall; (2) through the apical foramen by infusion into the material; (3) from outside the tooth through the exposed cementum, accessory canals, secondary canals, or defects in the coating surface; or (4) through the coronal access cavity.

For many years, apical leakage was thought to be the main cause of endodontic treatment failure. Based on their study using radioactive isotopes, Marshall and Masseler (1961) [4] were the first to report the effects of coronal leakage. Torabinejad et al. (1990) [1] then found bacterial products at the apex of root-filled tooth after 3 months in the absence of coronal restoration. In 1995, Ray and Trope [5•] published an important study showing a possible relationship between the quality of coronal restoration and the apical status of endodontically treated teeth. They posited that the quality of the coronal restoration has a greater effect than the quality of endodontic treatment on the periradicular status. According to Gillen et al. (2013) [6••], the data produced by Ray and Trope challenged the rationale of endodontics and stimulated intense discussion during the past 15 years. Although they reported 
that the chances for healing of apical periodontitis increase with both adequate root canal and restorative treatment, more attention has been paid to coronal leakage as a potential cause of endodontic failure since the study of Ray and Trope. Therefore, immediate restoration of endodontically treated teeth is recommended to prevent coronal leakage upon completion of root canal treatment $[7,8]$.

Root-filled teeth may be restored either directly by placing a restorative material into the tooth or indirectly by fabricating a composite resin, cast metal, or ceramic restoration. In cases in which retention is necessary for the final restoration, a post may be required. Regardless of the technique used, however, restoring root-filled teeth is a challenge because they are thought to be weaker and more susceptible to fracture than vital teeth. Several factors were evaluated as reasons for reduced fracture strength, including changes in the mechanical properties of dentine [9], changes in moisture content [10], time [11], and reduced levels of proprioception [12]. However, Sedgley and Messer (1992) [13] compared the biomechanical properties of endodontically treated teeth with those of their contralateral vital counterparts and concluded that teeth do not become more brittle following endodontic treatment.

Endodontic procedures reduce tooth stiffness by only $5 \%$, whereas restorative procedures are the greatest contributor to loss of tooth stiffness [14]. Indeed, the resistance of a root-filled tooth is directly related to the amount of tooth structure remaining $[13,15,16]$. Furthermore, tissue loss at either the radicular or coronal level influences the strain, failure mode, and stress distribution in endodontically treated teeth [17], resulting in significant biomechanical changes [14, 18, 19]. Even minimal structural loss, such as an I-shaped fissure [20], may change the stress dynamics. Figure 1 shows a three-dimensional (3D) finite elemental analysis (FEA) model of a premolar tooth. When an I-shaped fissure is added to the model (Fig. 1b) after loading, the stress moves forward toward the pulp and to the deeper parts of the tooth model. Based on this significant change in the integrity of the tooth with this slight anatomic alteration, clinicians can predict additional problems related to greater losses in tooth structure. Figure 1c shows the same model after a fissure sealant is applied, with the tooth regaining almost all of its ability to respond to occlusal loading. From a biomechanical perspective, this result indicates that restoration helps a tooth regain its initial response under loading.

During all phases of endodontic treatment, including the final restoration, it should be noted that the more coronal dentin that remains, the greater the chances for the tooth's survival $[21,22]$. To provide the most appropriate and long-lasting restoration, the clinician should pay close attention to the amount of coronal tooth structure remaining as well as the functional requirements [23].

\section{Direct Restoration of Endodontically Treated Teeth}

Endodontically treated teeth have reduced coronal and radicular tissue as a result of dental caries [14], operative procedures [24], intra-radicular procedures [25], and previous restorations [26], and restorative procedures that require extensive reduction of the tooth lead to further tissue loss [24, 27]. Cavity preparations lead to dental tissue loss, reducing the fracture strength of the remaining dental structure [28]. An occlusal cavity preparation reduces tooth stiffness by 14 to $44 \%$ and a mesio-occluso-distal (MOD) one by 20 to $63 \%$ [28]. Moreover, the presence of an endodontic access cavity further weakens a tooth [14, 24]. Because of such a limited amount of residual tooth structure, planning a restoration is challenging. Preserving a sound tooth structure should be the dentist's main goal, and a conservative approach should be taken to protect the remaining tissue.

\section{Glass Ionomer Cement}

Glass ionomer cement (GIC) has a long history of use in dentistry. Currently, several commercial hand-mixed and encapsulated GICs are available for various clinical purposes. Although the earliest forms could form stable physicochemical

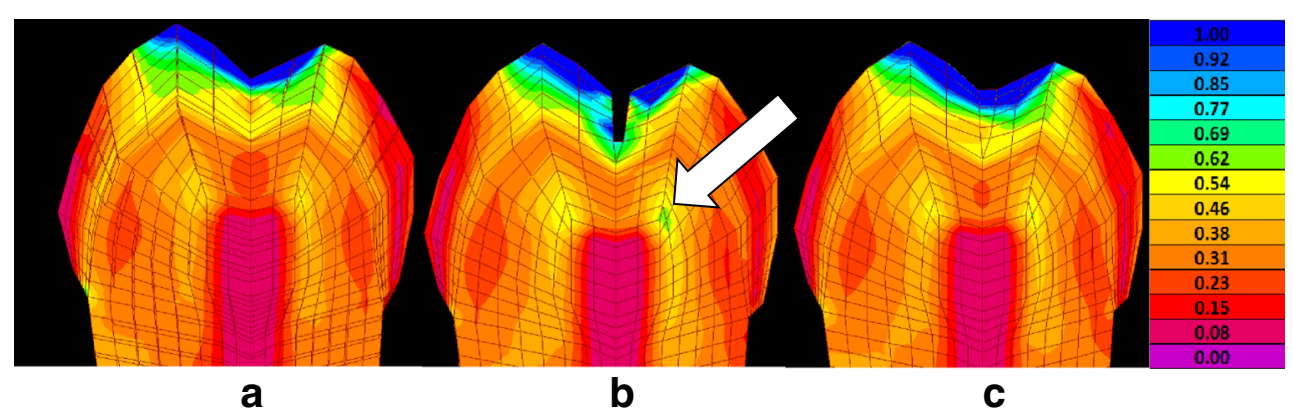

Fig. 1 a Sound mandibular premolar tooth model showing the stress distribution when loaded from the occlusal surface. The scale on the right shows the amount of stress in megapascals. Dark blue to green represents higher to lower stress. b Mandibular premolar tooth model with an I-type fissure. The fissure moves the stress forward to the deepest part of the crown and causes a high-stress accumulation (arrow) just near the pulp. c Mandibular premolar tooth model with an I-type fissure restored with sealant. Because of this restoration, the tooth regained almost all of its response to occlusal loading 
bonds to both enamel and dentin [29], they were rather brittle and ill-suited as a permanent filling material in the posterior region [30, 31]. Later, resin-modified GICs (RMGICs) and polyacid-modified composite resins (compomers) with better mechanical properties were developed. Compared with traditional GICs, RMGICs are more fracture resistant [32]. The resin component of the material makes it more viscoelastic, allowing it to relax under stress when used as a liner or base material under composite resin [33]. Although RMGICs and compomers both are appropriate materials for restoring primary teeth [34], they are less resistant than composites to crack propagation [35]; therefore, they should be used only in permanent teeth with minimal structure loss. The use of compomers in stress-bearing areas is not recommended [35], and these materials may not be appropriate for the final restoration of endodontically treated permanent teeth.

The recently introduced condensable GIC and a novel nano-filled resin coating material (Equia Restorative System; GC America, Alsip, IL) are reported to perform similarly to a microfilled hybrid composite in class 1 and 2 cavities at the end of 4 years [36]. However, no published data are available on the performance of these improved restorative materials in endodontically treated teeth; therefore, they should be used with caution.

\section{Dental Amalgam}

Bonded amalgam restorations show a generally improved adaptation [37]. However, amalgam is not an appropriate material for the final restoration of root-filled teeth, because it does not adhere to tooth structures [38]. Moreover, it must be retained in cavity preparations by retentive features that often require removal of a sound tooth structure [39]. Amalgam restorations have a propensity to deform under compressive loads [40] and have a higher thermal expansion coefficient compared with teeth $\left(8-11 \mathrm{ppm} /{ }^{\circ} \mathrm{C}\right)$ [41]. Restoration with amalgam after root canal treatment may result in the fracture of the root-filled tooth. However, a previous study reported that amalgam applied under a composite increased the resistance of root-filled premolars, unlike when teeth were restored with amalgam alone [42]. Because amalgam has an elastic modulus similar to that of resin composite and dentin [18], an amalgam-composite combination may be used in extended or deep cavities [43].

\section{Composite Resin Materials}

Restoration using direct composite resin is an excellent treatment option to conserve more tooth structure in root-filled teeth $[44,45]$. Direct restoration with composite resin provides more resistance against tooth fracture than amalgam, as well as providing intra-coronal reinforcement [18]. The results of a retrospective study confirm that cavities with up to three surfaces can be restored successfully with composite restoration using adhesive techniques [46]. However, the major shortcomings of composite resins, such as fracture within the body, margins of restoration, and polymerization shrinkage, remain a concern for clinicians $[44,47]$. Polymerization shrinkage generates stress at the tooth-restoration interface, and debonding occurs when the stress becomes greater than the bond's strength [47]. Cuspal deflection [48] and the risk of tooth fracture also increase [49]. Endodontic access and loss of the axial walls double the amount of cuspal displacement and strain [50]. Therefore, attempts to reduce stress in the remaining tooth structure and at the interfaces are crucial in endodontically treated teeth undergoing direct restoration with resin composite.

In the laboratory, many strategies have been developed to reduce stress, such as increasing the inorganic filler content, increasing the molecular weight per reactive group [51, 52], and developing composites with completely new resin matrices that do not shrink [53]. The clinical strategies suggested for minimizing the shrinkage stress of composites include incremental filling, soft-cure or pulse-delay cure methods, and use of a low-modulus intermediate liner material to absorb shrinkage stress [52]. The incremental filling technique has been recommended broadly for direct resin composite restoration, as bulk filling produces sudden shrinkage, does not allow the flow of composite to partially dissipate the shrinkage stress [54], and causes more cusp deflection compared with incremental layering techniques [48, 54].

The resin-dentin bonding area of composite resins has enough strain capacity to relieve stress in the resin materials [55]. The elasticity of the hybrid layer has a lower Young modulus than that of the restorative resin; therefore, this elastic area acts as an inherent buffer and compensates for the polymerization contraction of the restorative resin [56, 57]. FEA studies have shown the effect of the hybrid layer and its thickness on stress distribution and intensity in cervical restorations $[58,59]$ and its stress-relieving effect on premolars restored with direct composite resin [60]. Therefore, the stresses at the remaining tooth structure can be modified even by creating a hybrid layer through an adhesive resin under composite restoration. Use of an intermediate resin (e.g., a cavity liner or the base of low-viscosity/low-elastic modulus materials such as RMGICs, filled adhesives, and flowable composites) between the bonding agent and composite resin to act as an "elastic buffer" also has been suggested to reduce stress in the prepared cavities [61, 62]. However, conflicting results have been published on this topic. Some authors reported advantages with regard to marginal leakage, fracture strength, or cuspal deflection from an elastic lining using lowelastic modulus materials [52, 62], whereas others reported disadvantages [63] or could find no differences [49]. In a recent systematic review, Nguyen et al. (2014) [33] reported that a flowable resin composite lining is no better than resin composite restorations with no lining. 


\section{Fiber-Reinforced Composite Materials}

In 1999, Vallittu et al. [64] published a study on the flexural properties of acrylic resin polymers reinforced with unidirectional and woven glass fibers, reporting that the strain at the fracture of the material could be modified. Belli et al. (2005, 2006) $[65,66]$ evaluated fiber-reinforced composite resin restorations and concluded that using polyethylene fiber under composite restorations in root-filled teeth with MOD preparations significantly increases fracture strength, reduces leakage in class 2 cavities [67], and strengthens microtensile bonding to dentin [68]. Furthermore, fiber reinforcement between the restorative resin and dentin changes the fracture line, causes repairable fractures, saving the remaining tooth structure $[65$, $66,68]$, and increases the restorability of methacrylate-based composite resin-restored teeth after failure [69]. Although fiber-reinforced composite restorations are prone to aging due to exposure to the oral environment and the mechanical properties may deteriorate over time [70], one of the great benefits of this technology is the possibility of extending functional survival by repairing restorations in the oral cavity [71]. Deep endodontic access preparation in the MOD cavity has been found to increase cuspal deflection significantly [50]. Akman et al. (2011) [72] reported that fiber-reinforced composite restorations decrease cusp movement in molar teeth with MOD and endodontic access cavities. As a result, fiber reinforcement of composite resin restorations with polyethylene or glass fiber material is a well-accepted method for saving the remaining tooth structure while performing direct composite restorations in root-filled teeth.

Several studies suggest that cusp coverage along with composite resin materials minimizes tooth fracture and increases the durability of restorations [18, 73-75]. Others, however, indicate that cusp capping with the adhesive technique is not necessary in terms of cuspal fracture resistance in normal occlusion, especially in root-filled premolars [76-78] or if a fiber post is included [77]. A recent FEA study showed that palatal cusp reduction improves the biomechanics of a tooth restoration complex, consequently providing long-lasting clinical results [79]. Plotino et al. (2008) [44] restored endodontically treated molars to their original contours using direct or indirect composite resin and found no difference between the two techniques. According to Torabzadeh et al. (2013) [75], the success of direct restoration depends on the material used. Compressive loading during the fracture resistance test may be distributed throughout the restored tooth by different materials. Thus, Shafiei et al. (2014) [80] suggested covering the cusps with an amalgam and composite resin combination and found no difference between the group receiving direct composite coverage and the one undergoing amalgam-based composite restoration. Nevertheless, direct cusp coverage with composite restoration appears to be a reliable method in extensive cavities [44, 73].

\section{Silorane-Based Composite Materials}

Silorane-based composites have been marketed as an alternative to traditional methacrylate monomer-based composite resin restoratives. These hybrid systems contain both silorane- and oxirane-based monomers and have two main advantages: low polymerization shrinkage and increased hydrophobicity [53, 81]. Although Lien and Vandewalle (2010) [82] found the microhardness and compressive strength of the material to be low, silorane-based composites significantly increase the fracture strength of endodontically treated premolars [69] and decrease total cusp displacement in MOD cavities [81]. The addition of fiber had no effect on the strength of the restoration, whereas the use of a nano-ionomer core under the silorane-based restoration showed an advantage in terms of fracture strength [69].

\section{Bulk-Fill Flowable Base Materials}

In an effort to simplify clinical procedures, simplified dental adhesives [83], bulk-fill flowable base materials [84], and bulk-fill resin restorative materials [85] have been developed. Based on the results of randomized controlled studies, these low- and high-viscosity (sculptable) materials have proved successful [86, 87]; however, information regarding their performance in restoring root-filled teeth is lacking. One of these products, namely stress-decreasing material (SureFil SDR Flow; Dentsply, York, PA), was developed in an attempt to modify the dynamics of the polymerization reaction by slowing the polymerization rate. SDR includes a monomer that has a photoactive group in a urethane-based methacrylate resin [88]. In cavities lined with SDR, cuspal deflection is reduced significantly [84]. SDR results in less polymerization shrinkage compared with Filtek Supreme Flow (3M, St. Paul, $\mathrm{MN}$ ), Esthet X Flow (Dentsply), nano-hybrid and microhybrid composites, and silorane-based composites [89].

\section{Short-Fiber-Reinforced Composite Resin Materials}

Another base filling material option for restoring nonvital posterior teeth in high-stress-bearing areas is the short-fiberreinforced composite $[90,91]$. According to Garoushi et al. [91], randomly oriented E-glass fibers significantly affect the mechanical properties of the material and serve as a "crackstopper" layer. The load-bearing capacity may be increased by adding a continuous bidirectional or short random fiberreinforced composite substructure under the particulate filler composite resin [90]. In a 1-year clinical study [91], restorations combining the base of a short-fiber-reinforced composite resin as the substructure and the surface layer of a hybrid composite resin performed will in high-load-bearing areas. Yasa et al. (2015) [92] compared nano-hybrid composite resin, bulk-fill flowable composite, and short-fiber-reinforced composite in the absence/presence of retention slots. According to 
their study results, a short-fiber-reinforced composite with retentive slots may offer an alternative for preventing cuspal fracture of endodontically treated teeth with MOD cavities.

\section{Intra-Coronal Barrier Materials}

Intra-coronal barriers generally are used if immediate restoration of the tooth is not possible. Intra-orifice barriers strengthen the fracture resistance of endodontically treated teeth compared with root-filled teeth without them [93]. GICs, fissure sealants, conventional and flowable composite resins, and mineral trioxide aggregate (MTA) may be used for this purpose [94]. Tay and Pashley (2007) [95] reviewed the techniques for creating monoblock units in the endodontic field. Although the creation of these monoblocks in endodontically treated teeth seems practically difficult, several researchers reported the positive effects of monoblock units in terms of stress distribution and fracture strength resistance [96]. The elastic modulus of dentin is about 18.6 GPa [95]; based on the elastic modulus of portland cement, the elastic modulus of MTA is reported to be similar to that of dentin $[95,96]$. Therefore, replacing the missing dentin structure with MTA appears to be an effective way to create successful postendodontic restorations. The reinforcing effect of MTA in immature teeth has been well studied [97]; however, its effects when used at the coronal surface under the permanent direct filling have not been studied yet.

A new calcium-silicate restorative material was produced recently under the trademark Biodentine (Septodont, Lancaster, PA). The manufacturer introduced this product not only as an endodontic repair material but also as a replacement for coronal dentin. Its adhesion to the dentin surface was found to be superior to that of both GIC and MTA [98]. When used as a dentin substitute material in "open sandwich" class II restorations, Biodentine performed similarly to GIC [99]. Although this material was found to be weak in its early phases [100], Biodentine seems promising as a coronal restorative material.

\section{Conclusions}

Currently, coronal leakage is thought to be as important as apical leakage and has a significant effect on the outcome of endodontic treatment. Therefore, immediate restoration after root canal treatment is recommended. Tissue loss at either the radicular or coronal level influences the strain, failure mode, and stress distribution in endodontically treated teeth; therefore, it is important to consider the structure of the remaining tooth when selecting the material and technique. Amalgam must be retained in cavity preparations by retentive features that usually require the removal of additional tooth structure. Moreover, it does not adhere to tooth structures and therefore cannot be considered an appropriate material for the final restoration of root-filled teeth. The amalgam-composite combination, however, may be used in extended or deep cavities.

Direct composite restoration of root-filled teeth is still the most frequently used technique. To overcome the problems associated with shrinkage stress of the material, fiber reinforcement techniques may be applied or low-viscosity materials may be used as a liner.

A paradox exists among researchers regarding the coverage of cusps with composite resin. Overall, direct cusp coverage with composite restoration appears to be a reliable method for treating extensive cavities. Cusp deflection may be a great problem in endodontically treated premolar teeth and may cause unrestorable fractures. Silorane-based composites may be used to decrease the total cusp displacement in premolars with MOD cavities. Low- and high-viscosity bulk-fill composite resins also may be used safely in composite resin restoration. Restorations combining the base of a short-fiberreinforced composite resin as a substructure and the surface layer of a hybrid composite resin show promise in terms of their performance in high-load-bearing areas.

Recent improvements in glass ionomer materials have led to successful restorations, although improved GICs still should be used with caution. RMGICs and compomers are less resistant than composites to crack propagation; therefore, they should be used only in permanent teeth with minimal structure loss. The use of compomers in stress-bearing areas is not recommended.

The presence of intra-orifice barriers strengthens the fracture resistance of endodontically treated teeth. Although there are few studies on the effect of MTA and Biodentine on the fracture strength of root-filled teeth when used as coronal restorative materials, Biodentine appears promising in this regard.

Acknowledgments Supported in part by Scientific Research Projects Coordination Center (BAP) of Selcuk University, Konya, Turkey.

\section{Compliance with Ethics Guidelines}

Conflict of Interest The authors have nothing to disclose.

Human and Animal Rights and Informed Consent This article does not contain any studies with human or animal subjects performed by any of the authors.

\section{References}

Papers of particular interest, published recently, have been highlighted as:

- Of importance

•• Of major importance

1. Torabinejad M, Ung B, Kettering JD. In vitro bacterial penetration of coronally unsealed endodontically treated teeth. J Endod. 1990;16:566-9. 
2. Saunders WP, Saunders EM. Coronal leakage as a cause of failure in root-canal therapy: a review. Endod Dent Traumatol. 1994;10: $105-8$.

3. Limkangwalmongkol S, Burtscher P, Abbott PV, et al. A comparative study of the apical leakage of four root canal sealers and laterally condensed gutta-percha. J Endod. 1991;17(10):495-9.

4. Marshall FS, Massler M. The sealing of pulpless teeth evaluated with radioisotopes. J Dent Med. 1961;16L:172-84.

5. Ray HA, Trope M. Periapical status of endodontically treated teeth in relation to the technical quality of the root filling and the coronal restoration. Int Endod J. 1995;28:12-8. In this article, the authors indicate that the quality of the coronal restoration has a greater effect than that of endodontic treatment on the periradicular status. However, this study is limited in that it was based on retrospective radiographic data as well as other retrospective studies. Yet, we must acknowledge that this article challenged the rationale of endodontics, leading to more attention being paid to coronal leakage as a potential cause of endodontic failure.

6.• Gillen BM, Looney SW, Gu LS, et al. Impact of the quality of coronal restoration versus the quality of root canal fillings on success of root canal treatment: a systematic review and meta-analysis. J Endod. 2011;37(7):895-902. This systematic review and meta-analysis was planned to re-evaluate whether the quality of a coronal restoration or the quality of a root canal filling has a greater impact on the outcome of root canal treatment. The authors concluded that the odds for healing of apical periodontitis improve with both adequate root canal treatment and adequate restorative treatment.

7. Heling I, Gorfil C, Slutzky H, et al. Endodontic failure caused by inadequate restorative procedures: review and treatment recommendations. J Prosthet Dent. 2002;87(6):674-8.

8. Tewari S, Tewari S. Assessment of coronal microleakage in intermediately restored endodontic access cavities. Oral Surg Oral Med Oral Pathol Oral Radiol Endod. 2002;93(6):716-9.

9. Soares CJ, Santana FR, Silva NR, et al. Influence of the endodontic treatment on mechanical properties of root dentin. J Endod. 2007;33(5):603-6.

10. Papa J, Cain C, Messer HH. Moisture content of vital vs endodontically treated teeth. Endod Dent Traumatol. 1994;10(2):91-3.

11. Lewinstein I, Grajower R. Root dentin hardness of endodontically treated teeth. J Endod. 1981;7(9):421-2.

12. Randow K, Glantz PO. On cantilever loading of vital and nonvital teeth. An experimental clinical study. Acta Odontol Scand. 1986;44(5):271-7.

13. Sedgley CM, Messer HH. Are endodontically treated teeth more brittle? J Endod. 1992;18(7):332-5.

14. Reeh ES, Messer HH, Douglas WH. Reduction in tooth stiffness as a result of endodontic and restorative procedures. J Endod. 1989;15(11):512-6.

15. Patel A, Gutteridge DL. An in vitro investigation of cast post and partial core design. J Dent. 1996;24:281-7.

16. Marchi GM, Mitsui FH, Cavalcanti AN. Effect of remaining dentine structure and thermal-mechanical aging on the fracture resistance of bovine roots with different post and core systems. Int Endod J. 2008;41(11):969-76.

17. Veríssimo C, Simamoto Júnior PC, Soares CJ, et al. Effect of the crown, post, and remaining coronal dentin on the biomechanical behavior of endodontically treated maxillary central incisors. J Prosthet Dent. 2014;111(3):234-46.

18. Soares PV, Santos-Filho PC, Martins LR, et al. Influence of restorative technique on the biomechanical behavior of endodontically treated maxillary premolars. Part I: fracture resistance and fracture mode. J Prosthet Dent. 2008;99:30-7.
19. Ribeiro FC, Souza-Gabriel AE, Marchesan MA, et al. Influence of different endodontic filling materials on root fracture susceptibility. J Dent. 2008;36(1):69-73.

20. Hirano Y, Aoba T. Computer-assisted reconstruction of enamel fissures and carious lesions of human premolars. J Dent Res. 1995;74(5):1200-5.

21. Naumann M, Blankenstein F, Kiessling S, et al. Risk factors for failure of glass fiber-reinforced composite post restorations: a prospective observational clinical study. Eur J Oral Sci. 2005;113(6): 519-24.

22. Ferrari M, Cagidiaco MC, Goracci C, et al. Long-term retrospective study of the clinical performance of fiber posts. Am J Dent. 2007;20(5):287-91.

23. Schwartz RS, Robbins JW. Post placement and restoration of endodontically treated teeth: a literature review. J Endod. 2004;30: 289-301.

24. Panitvisai P, Messer HH. Cuspal deflection in molars in relation to endodontic and restorative procedures. J Endod. 1995;21(2):5761.

25. Rao MS, Shameem A, Nair R, et al. Comparison of the remaining dentin thickness in the root after hand and four rotary instrumentation techniques: an in vitro study. J Contemp Dent Pract. 2013;14(4):712-7.

26. Lin CL, Chang CH, Ko CC. Multifactorial analysis of an MOD restored human premolar using auto-mesh finite element approach. J Oral Rehabil. 2001;28:576-85.

27. Mondelli RF, Barbosa WF, Mondelli J. Fracture strength of weakened human premolars restored with amalgam with and without cusp coverage. Am J Dent. 1998;11:181-4.

28. Larson TD, Douglas WH, Geistfeld RE. Effect of prepared cavities on the strength of teeth. Oper Dent. 1981;6:2-5.

29. Glasspoole EA, Erickson RL, Davidson CL. Effect of surface treatments on the bond strength of glass ionomers to enamel. Dent Mater. 2002;18:454-62.

30. Mount GJ. Buonocore memorial lecture. Glass-ionomer cements: past, present and future. Oper Dent. 1994;19:82-90.

31. Naasan MA, Watson TF. Conventional glass ionomers as posterior restorations. A status report for the American Journal of Dentistry. Am J Dent. 1998;11:36-45.

32. Ilie N, Hickel R, Valceanu AS, et al. Fracture toughness of dental restorative materials. Clin Oral Investig. 2012;16(2):489-98.

33. Nguyen K, Sathorn C, Wong R, et al. Clinical performance of laminate and non-laminate resin composite restorations: a systematic review. Aust Dent J. 2014. doi:10.1111/adj.12252. 17.

34. Qvist V, Laurberg L, Poulsen A, et al. Class II restorations in primary teeth: 7 years study on three resin-modified glass ionomer cements and a compomer. Eur J Oral Sci. 2004;112(2):188-96.

35. Yap AU, Chung SM, Chow WS, et al. Fracture resistance of compomer and composite restoratives. Oper Dent. 2004;29(1): 29-34.

36. Gurgan S, Kutuk ZB, Ergin E, et al. Four-years randomized clinical trial to evaluate the clinical performance of a glass ionomer restorative system. Oper Dent. 2015;40(2):134-43.

37. Ahrari F, Nojoomian M, Moosavi H. Clinical evaluation of bonded amalgam restorations in endodontically treated premolar teeth: a 1 year evaluation. J Contemp Dent Pract. 2010;11(5):009-16.

38. Mondelli J, Steagall L, Ishikiriama A, et al. Fracture strength of human teeth with cavity preparations. J Prosthet Dent. 1980;43: 419-22.

39. Pradeep P, Kumar VS, Bantwal SR, et al. Fracture strength of endodontically treated premolars: an in-vitro evaluation. J Int Oral Health. 2013;5(6):9-17.

40. Linn J, Messer HH. Effect of restorative procedures on the strength of endodontically treated molars. J Endod. 1994;20:479-85. 
41. Seo DG, Yi YA, Shin SJ, et al. Analysis of factors associated with cracked teeth. J Endod. 2012;38(3):288-92.

42. Geiger S, Paikin L, Gorfil C, et al. Fracture resistance of endodontically treated teeth restored with combined composite-amalgam restorations. Quintessence Int. 2008;39(2):e58-62.

43. Plasmen PJ, Reukers EA. Esthetic veneering of amalgam restorations with composite resin - combining the best of both worlds? Oper Dent. 1993;18(2):66-71.

44. Plotino G, Buono L, Grande NM, et al. Fracture resistance of endodontically treated molars restored with extensive composite resin restorations. J Prosthet Dent. 2008;99(3):225-32.

45. Mannocci F, Bertelli E, Sherriff M, et al. Three-years clinical comparison of survival of endodontically treated teeth restored with either full cast coverage or with direct composite restoration. Int Endod J. 2009;42(5):401-5.

46. Dammaschke T, Nykiel K, Sagheri D, et al. Influence of coronal restorations on the fracture resistance of root canal-treated premolar and molar teeth: a retrospective study. Aust Endod J. 2013;39(2):48-56.

47. Ferracane JL. Developing a more complete understanding of stresses produced in dental composites during polymerization. Dent Mater. 2005;21:36-42.

48. Lee MR, Cho BH, Son HH, et al. Influence of cavity dimension and restoration methods on the cusp deflection of premolars in composite restoration. Dent Mater. 2007;23:288-95.

49. Alomari QD, Reinhardt JW, Boyer DB. Effect of liners on cusp deflection and gap formation in composite restorations. Oper Dent. 2001;26(4):406-11.

50. Taha NA, Palamara JE, Messer HH. Cuspal deflection, strain and microleakage of endodontically treated premolar teeth restored with direct resin composites. J Dent. 2009;37(9):724-30.

51. Braga RR, Ferracane JL. Alternatives in polymerization contraction stress management. Crit Rev Oral Biol Med. 2004;15:17684.

52. Kwon Y, Ferracane J, Lee IB. Effect of layering methods, composite type, and flowable liner on the polymerization shrinkage stress of light cured composites. Dent Mater. 2012;28(7):801-9.

53. Weinmann W, Thalacker C, Guggenberger R. Siloranes in dental composites. Dent Mater. 2005;21:68-74.

54. Park J, Chang J, Ferracane J, et al. How should composite be layered to reduce shrinkage stress: incremental or bulk filling? Dent Mater. 2008;24(11):1501-5.

55. Van Meerbeek B, Willems G, Celis JP, et al. Assessment by nanoindentation of the hardness and elasticity of the resin-dentin bonding area. J Dent Res. 1993;72(10):1434-42.

56. Kemp-Scholte CM, Davidson CL. Marginal integrity related to bond strength and strain capacity of composite resin restorative systems. J Prosthet Dent. 1990;64:658-64.

57. Uno S, Finger WJ. Function of the hybrid zone as a stressabsorbing layer in resin-dentin bonding. Quintessence Int. 1995;26(10):733-8.

58. Eliguzeloglu E, Eraslan O, Omurlu H, et al. Effect of hybrid layer and thickness on stress distribution of cervical wedge-shaped restorations. Eur J Dent. 2010;4(2):160-5.

59. Eliguzeloglu E, Eraslan O, Omurlu $\mathrm{H}$, et al. The effect of cavity shape and hybrid layer on the stress distribution of cervical composite restorations. Eur J Dent. 2011;5(2):180-5.

60. Belli S, Eskitașcioglu G, Eraslan O, et al. Effect of hybrid layer on stress distribution in a premolar tooth restored with composite or ceramic inlay: an FEM study. J Biomed Mater Res B Appl Biomater. 2005; 74(2):665-8.

61. Van Meerbeek B, Inokoshi S, Braem M, et al. Morphological aspects of the resin-dentin interdiffusion zone with different dentin adhesive systems. J Dent Res. 1992;71(8):1530-40.

62. Belli S, Inokoshi S, Ozer F, et al. The effect of additional enamel etching and a flowable composite to the interfacial integrity of class II adhesive composite restorations. Oper Dent. 2001;26(1): $70-5$.

63. Liveira LC, Duarte Jr S, Araujo CA, et al. Effect of low-elastic modulus liner and base as stress-absorbing layer in composite resin restorations. Dent Mater. 2010;26(3):e159-69.

64. Vallittu PK. Flexural properties of acrylic resin polymers reinforced with unidirectional and woven glass fibers. J Prosthet Dent. 1999;81(3):318-26.

65. Belli S, Erdemir A, Ozcopur M, et al. The effect of fibre insertion on fracture resistance of root filled molar teeth with MOD preparations restored with composite. Int Endod J. 2005;38(2):73-80.

66. Belli S, Erdemir A, Yildirim C. Reinforcement effect of polyethylene fibre in root-filled teeth: comparison of two restoration techniques. Int Endod J. 2006;39(2):136-42.

67. Belli S, Orucoglu H, Yildirim C, et al. The effect of fiber placement or flowable resin lining on microleakage in class II adhesive restorations. J Adhes Dent. 2007;9(2):175-81.

68. Belli S, Dönmez N, Eskitaşcioğlu G. The effect of c-factor and flowable resin or fiber use at the interface on microtensile bond strength to dentin. J Adhes Dent. 2006;8(4):247-53.

69. Shafiei F, Tavangar MS, Ghahramani Y, et al. Fracture resistance of endodontically treated maxillary premolars restored by silorane-based composite with or without fiber or nano-ionomer. J Adv Prosthodont. 2014;6(3):200-6.

70. Frese C, Decker C, Rebholz J, et al. Original and repair bond strength of fiber-reinforced composites in vitro. Dent Mater. 2014;30(4):456-62.

71. Wolff D, Schach C, Kraus T, et al. Fiber-reinforced composite fixed dental prostheses: a retrospective clinical examination. J Adhes Dent. 2011;13:187-94.

72. Akman S, Akman M, Eskitascioglu G, et al. Influence of several fibre-reinforced composite restoration techniques on cusp movement and fracture strength of molar teeth. Int Endod J. 2011;44(5): 407-15.

73. Mondelli RF, Ishikiriama SK, de Oliveira FO, et al. Fracture resistance of weakened teeth restored with condensable resin with and without cusp coverage. J Appl Oral Sci. 2009;17(3):161-5.

74. Xie KX, Wang XY, Gao XJ, et al. Fracture resistance of root filled premolar teeth restored with direct composite resin with or without cusp coverage. Int Endod J. 2012;45(6):524-9.

75. Torabzadeh H, Ghasemi A, Dabestani A, et al. Fracture resistance of teeth restored with direct and indirect composite restorations. J Dent (Tehran). 2013;10(5):417-25.

76. Krejci I, Duc O, Dietschi D, et al. Marginal adaptation, retention and fracture resistance of adhesive composite restorations on devital teeth with and without posts. Oper Dent. 2003;28:127-35.

77. Mohammadi N, Kahnamoii MA, Yeganeh PK, et al. Effect of fiber post and cusp coverage on fracture resistance of endodontically treated maxillary premolars directly restored with composite resin. J Endod. 2009;35:1428-32.

78. Scotti N, Scansetti M, Rota R, et al. The effect of the post length and cusp coverage on the cycling and static load of endodontically treated maxillary premolars. Clin Oral Investig. 2011;15:923-9.

79. Kantardzić I, Vasiljević D, Blazić L, et al. Influence of cavity design preparation on stress values in maxillary premolar: a finite element analysis. Croat Med J. 2012;53(6):568-76.

80. Shafiei F, Memarpour M, Karimi F. Fracture resistance of cuspal coverage of endodontically treated maxillary premolars with combined composite-amalgam compared to other techniques. Oper Dent. 2011;36(4):439-47.

81. Palin WM, Fleming GJ, Burke FJ, et al. The influence of short and medium-term water immersion on the hydrolytic stability of novel low-shrink dental composites. Dent Mater. 2005;21(9):852-63.

82. Lien W, Vandewalle KS. Physical properties of a new siloranebased restorative system. Dent Mater. 2010;26(4):337-44. 
83. Van Meerbeek B, Yoshihara K, Yoshida Y, et al. State of the art of self-etch adhesives. Dent Mater. 2011;27:17-28.

84. Moorthy A, Hogg $\mathrm{CH}$, Dowling $\mathrm{AH}$, et al. Cuspal deflection and microleakage in premolar teeth restored with bulk-fill flowable resin-based composite base materials. J Dent. 2012;40:500-5.

85. Fleming GJ, Awan M, Cooper PR, et al. The potential of a resinbased composite to be cured to a $4 \mathrm{~mm}$ depth. Dent Mater. 2008;24:522-9.

86. Manhart J, Chen HY, Hickel R. Clinical evaluation of the posterior composite Quixfil in class I and II cavities: 4 years follow-up of a randomized controlled trial. J Adhes Dent. 2010;12(3):237-43.

87. Van Dijken JW, Pallesen U. A randomized controlled three years evaluation of "bulk-filled" posterior resin restorations based on stress decreasing resin technology. Dent Mater. 2014;30(9): e245-51.

88. Jin X, Bertrand S, Hammesfahr PD. New radically polymerizable resins with remarkably low curing stress. J Dent Res. 2009;88: 1651.

89. Ilie N, Hickel R. Investigations on a methacrylate-based flowable composite based on the SDR ${ }^{\mathrm{TM}}$ technology. Dent Mater. 2011;27(4):348-55.

90. Garoushi SK, Lassila LV, Tezvergil A, et al. Load bearing capacity of fiber-reinforced and particulate filler composite resin combination. J Dent. 2006;34:179-84.

91. Garoushi S, Tanner J, Vallittu P, et al. Preliminary clinical evaluation of short fiber-reinforced composite resin in posterior teeth: 12 months report. Open Dent J. 2012;6:41-5.
92. Yasa B, Arslan H, Yasa E, et al. Effect of novel restorative materials and retention slots on fracture resistance of endodonticallytreated teeth. Acta Odontol Scand. 2015;18:1-7.

93. Aboobaker S, Nair BG, Gopal R, et al. Effect of intra-orifice barriers on the fracture resistance of endodontically treated teeth — an ex-vivo study. J Clin Diagn Res. 2015;9(2):ZC17-20.

94. Baba NZ, Goodacre CJ. Restoration of endodontically treated teeth: contemporary concepts and future perspectives. Endod Top. 2014;31(1):68-83.

95. Tay FR, Pashley DH. Monoblocks in root canals: a hypothetical or a tangible goal. J Endod. 2007;33(4):391-8.

96. Belli S, Eraslan O, Eskitascioglu G, et al. Monoblocks in root canals: a finite elemental stress analysis study. Int Endod J. 2011;44(9):817-26.

97. Milani AS, Rahimi S, Borna Z, et al. Fracture resistance of immature teeth filled with mineral trioxide aggregate or calciumenriched mixture cement: an ex vivo study. Dent Res J (Isfahan). 2012;9(3):299-304.

98. Kaup M, Dammann CH, Schäfer E, et al. Shear bond strength of Biodentine, ProRoot MTA, glass ionomer cement and composite resin on human dentine ex vivo. Head Face Med. 2015;11:14.

99. Aggarwal V, Singla M, Yadav S, et al. Marginal adaptation evaluation of Biodentine and MTA plus in "open sandwich" class II restorations. J Esthet Restor Dent. 2015;27(3):167-75.

100. Hashem DF, Foxton R, Manoharan A, et al. The physical characteristics of resin composite-calcium silicate interface as part of a layered/laminate adhesive restoration. Dent Mater. 2014;30(3): 343-9. 